\title{
COMO AS FAVELAS NOS AJUDAM A PENSAR A CIDADE APÓS A PANDEMIA DO CORONAVÍRUS?
}

\section{How do the slums help us think about the city after the coronavirus pandemic? \\ ?Cómo nos ayudan las favelas a pensar en la ciudad después de la pandemia del coronavirus?}

Mário Pires Simão

Universidade do Estado do Rio de Janeiro. mariosimao.uerj@gmail.com

Artigo enviado para publicação em 24/04/2020 e aceito em 28/04/2020

DOI: $10.12957 /$ tamoios.2020.50437

\begin{abstract}
Resumo
Este ensaio tem como objetivo relacionar os atuais contextos da pandemia do novo coronavírus às periferias urbanas, em especial, às favelas. Entendemos que a pandemia constitui uma oportunidade para refletir sobre nosso grave quadro de desigualdade social e sobre o desafio que se impõe à sociedade brasileira para pensar a cidade para além da lógica capitalista, reconhecendo um urbanismo periférico ou subalterno como uma das respostas potentes e inventivas da luta pelo direito à cidade.
\end{abstract}

Palavras-chave: favelas, cidade, urbanização, práticas sociais, periferia

\section{Abstract}

This essay aims to relate the current contexts of the new coronavirus pandemic with urban peripheries, especially slums. We understand that the pandemic is an opportunity to reflect on our serious situation of social inequality and on the challenge that Brazilian society is required to think about the city beyond the capitalist logic, recognizing a peripheral or subaltern urbanism as one of the powerful and inventive to the struggle for the right to the city.

Keywords: slums, city, urbanization, social practices, peripherie

\section{Resumen}

Este ensayo pretende relacionar los contextos actuales de la pandemia del nuevo coronavirus con las periferias urbanas, especialmente con los barrios marginales. Entendemos que la pandemia es uma oportunidad para reflexionar sobre nuestra grave situación de desigualdad social y sobre el desafio que la sociedad brasileña impone para pensar en la ciudad más allá de la lógica capitalista, reconocer un urbanismo periférico o subalterno como una de las respuestas poderosas e inventivas de la lucha por el derecho a la ciudad.

Palabras-clave: favelas, ciudad, urbanización, prácticas sociales, periferia 


\section{Introdução}

Dizer que o ser humano não veio ao mundo a passeio soa completamente pueril. Mas se há uma coisa que a história mostra é a indiscutível capacidade desta espécie de sobreviver a problemas de robustas grandezas. Foi assim ainda nos tempos mais primórdios, enfrentando uma natureza ainda muito hostil e manteve-se ao longo de sua ainda curta permanência no planeta, defrontando-se com monstros, alguns destes engendrados pelas suas próprias formas societárias.

Atualmente estamos diante de mais um destes grandes enfrentamentos, a saber, uma epidemia de gripe, provocada por um vírus altamente contagioso, denominada pelos cientistas de COVID-19, que por sua acelerada contaminação ganhou proporções pandêmicas.

Diante do rápido contágio, autoridades públicas das diferentes nações, sejam estas consideradas desenvolvidas ou não, se depararam com a iminência do colapso de seus sistemas de atendimento hospitalar e, consequentemente, com um cenário inequívoco de crescimento do número de vítimas fatais nas mais diferentes regiões e cidades de seus países. Por sua vez, autoridades médicas e sanitárias, pesquisadores e intelectuais dos distintos campos científicos são, em geral, unânimes quanto à situação de calamidade que se avizinha. Em 23 de abril de 2020, o Worldometer, site internacional que disponibiliza estatísticas mundiais, contabilizava mais de dois milhões e seiscentas mil pessoas infectadas no mundo e quase duzentos mil óbitos. E esse número cresce a um ritmo bastante veloz se comparado com outras doenças contagiosas que já assolaram o mundo em outros tempos.

Embora as análises apontem para este ritmo acelerado de contágio, isto depende de um conjunto de variáveis que vão desde a localização, a distribuição da população no território, as condições sanitárias e de saúde de cada região do planeta, as ações postas em prática pelas autoridades públicas em cada uma destas regiões e também da própria disposição das populações quanto à recepção das informações e seus modos de agir em situações de crise. E apesar do discurso, já recorrente, sobre a pandemia atingir a todos, independente da condição das pessoas, não resta dúvida de que as possibilidades de enfrentamento e superação do problema não são e não serão as mesmas para todos e todas.

Contudo, catástrofes desta magnitude sempre trazem alertas importantes para a sociedade e se tornam uma oportunidade para que algumas indagações venham à baila, principalmente a respeito dos nossos arranjos societários e seus artefatos sociais, culturais, tecnológicos que, se por um lado, são celebrados como avanços para o nosso modo de vida, por outro também são produtores de monstros cada vez mais assustadores e potencialmente destruidores de nós mesmos.

Neste sentido, queremos aqui neste ensaio apontar certas correspondências entre o enfrentamento da pandemia e a superação das desigualdades sociais que, inequivocamente, são traços da realidade brasileira e podem ser interpretadas em seu potencial destrutivo, mas também podem alimentar a luta contra os monstros, visíveis, invisíveis ou invisibilizados que nos assombram e nos colocar em outro patamar societário.

Seguramente a desigualdade social é um fenômeno bastante difuso no País. Embora o indicador de renda seja o critério mais citado no âmbito da opinião pública, há tempos as instituições que produzem dados ou análises estatísticas já operam com o cruzamento de informações de caráter econômico, social, cultural. Se reconhece a indissociabilidade entre renda, raça, gênero, por exemplo, assim como é inevitável um esforço analítico-comparativo entre regiões, entre campo e cidade, um empreendimento escalar para entender em que medida os indicadores se tornam mais salientes ou não. 
Não pretendemos nos deter na descrição de dados sobre a desigualdade, visto que outras análises mais extensas cumprem perfeitamente esta função. No âmbito deste ensaio, ao correlacionar pandemia e desigualdade social, o nosso ponto de inflexão é a periferia urbana brasileira, em especial as favelas, espaços de morada que no país abriga, em proporções distintas, uma parcela significativa de sua população. Segundo o IBGE, órgão responsável pelas estatísticas oficiais brasileiras, a população residente nos tais aglomerados subnormais ${ }^{1}$ aumentou em mais de 60\% entre os anos de 1991 e 2010.

$\mathrm{Na}$ cidade do Rio de Janeiro, por exemplo, $22 \%$ da população vive em favelas (IPP, 2016). Em São Paulo este número alcança 11\%. Em Belo Horizonte, $13 \%$ da população habita o que é denominado aglomerado subnormal. Os dados são reveladores da dramaticidade da vida urbana.

Mas pensar a chegada da pandemia nestes territórios não pode ser algo restrito a escala local e a medidas estritamente emergenciais. O pensamento científico dispõe de ferramentas de método para que ampliemos nossos enquadramentos temporais e espaciais para olhar os fenômenos. O pensamento dialético nos impulsiona a indagar que parâmetros históricos e materiais podem ser acionados no enfrentamento de uma crise imposta por um vírus letal numa sociedade crivada pela desigualdade social, em que mais da metade da população mundial, segundo o Banco Mundial, luta para satisfazer as necessidades básicas e o Brasil é uma das expressões mais nítidas do imenso abismo de direitos e oportunidades entre os cidadãos.

Visto que estas disparidades são condizentes ao modo como nos organizamos socialmente, são também mediadas espacialmente e temporalmente. Assim, nossos sistemas gregários, nossas estratégias de sobrevivência, de sociabilidade são todos social e culturalmente produzidos. Pensamos, projetamos, produzimos, reproduzimos as cidades. É um produto do que somos e, ao mesmo tempo, incide sobre nós mesmos.

Então cabe nos questionar sobre nossos modelos de urbano, sob os referenciais da vida moderna. Viver em áreas urbanas, segundo as Nações Unidas é hoje a realidade de pouco mais da metade da população mundial, o que deve se ampliar bastante nas próximas décadas. No Brasil de acordo com a Pesquisa Nacional por Amostra de Domicílios (PNAD 2015) quase $85 \%$ da população vive em áreas urbanas. Mas são estas áreas ambientes saudáveis, seguros, acolhedores para todos os seus cidadãos e cidadãs? E a forma como as projetamos para o futuro harmoniza com um padrão de vida digna para todos e todas?

Algumas destas perguntas são respondidas pelo modo como projetamos o urbanismo contemporâneo. Embora exista uma pluralidade de leituras e proposições sobre a cidade, ainda prevalecem os discursos de um urbanismo que escapa dos padrões estabelecidos. As favelas como espaços de uma periferia inculta, incivilizada, ilegal e ilegítima exemplificam o que estamos falando. Padecemos de um urbanismo um tanto míope, que restringe seu foco a poucos arranjos sócio-espaciais. E, consequentemente, se arvora o direito de narrar a cidade somente a partir destes parâmetros e, não simplesmente narrar, mas classificar, sub-notificar, inferiorizar. Dedicaremos a primeira parte deste trabalho a este debate.

Decerto que os parâmetros estão em questão, sobretudo quando nos deparamos com crises sanitárias e de saúde como a que estamos vivendo. Diferentes estudos recusam reduzir a experiência urbana a uma visão estereotipada e desqualificada. A noção de urbanismo subalterno desenvolvida por Roy (2017), por exemplo, contrapõe às narrativas dominantes da megacidade, as favelas, espaços das classes subalternas, como terrenos de habitação, subsistência e política. O que nos remete ao desafio de pensar o urbano sob outro paradigma e, por conseguinte, discutir os espaços periféricos, como as favelas, para 
além do discurso hegemônico da pobreza, da desordem e da anomia. Este será nosso caminho na segunda parte do texto.

Por fim, na terceira parte, alçamos alguns elementos características das favelas para discutir os desafios que temos a frente para pensar as cidades. Silva e Barbosa (2005) indicam que o futuro das favelas não pode ser cogitado sem que pensemos os rumos da cidade como um todo. No caso aqui a inversão é legítima. Não podemos refletir qual cidade queremos sem que tenhamos as favelas, seus moradores e suas práticas sociais também como referência. Por isso cabe, em tempos de pandemia, discutir as formas de apropriação do espaço urbano. É lamentável que a humanidade tenha que passar por eventos como esse para se alertar sobre os riscos que nossos modelos de pensar e construir as cidades trazem para a vida humana plena de dignidade.

\section{As favelas como territórios da suburbanização}

Favelas, vilas, mocambos, entre outros espaços populares, fazem parte das cidades brasileiras há mais de um século. Suas origens remontam ao final do século XIX e início do século XX. Gonçalves assinala a dificuldade para se determinar o momento exato em que surgiram as primeiras favelas no Rio de Janeiro (2013, p. 44). Campos (2005, p.55) relaciona tais territórios às estruturas dos antigos quilombos periurbanos para onde iam os negros libertos pós-abolição da escravidão, asseverando este contexto como uma versão possível do surgimento das primeiras formas de habitação que posteriormente seriam denominadas de favelas.

Não retomaremos essa história, já retratada por diferentes autores (ABREU, 1997; VALLADARES, 2005; SILVA e BARBOSA, 2005; ZALUAR e ALVITO, 2006, entre outros). Mas há certo consenso que a gênese, difusão e consolidação das favelas no cenário brasileiro estão atreladas à dinâmica urbana num contexto de incipiente, mas progressiva industrialização e transformação das cidades no espaço privilegiado para o desenvolvimento de um modelo produtivo e societário de matriz capitalista.

Neste contexto, a multiplicação das favelas nas cidades brasileiras é, indubitavelmente, um indicador dos limites de acesso à habitação para uma fração da população. Contudo, a ausência ou negligência de instrumentos políticos de habitação que se dirigissem efetivamente a esta parte dos residentes das cidades, associadas ao processo de transformação do urbano em espaços metropolitanos, conforme menciona Abreu (1997, p. 93-94), explicam um processo de crescimento expressivo de subúrbios e, consequentemente, dos espaços denominados como favelas, territórios onde os investimentos públicos e privados, tanto no que tange à questão urbanística, quanto no que se refere aos direitos sociais, são predominantemente precários.

Apesar da aparente contradição por gerar precariedade, a produção de um urbano desigual corresponde aos parâmetros de um sistema que opera sob a ótica da acumulação. A crise com a produção de enormes espaços periféricos, que abarcavam as frações mais pobres da população urbana, foi inclusive aplacada pelo fato de que estes espaços cumpriam um papel fundamental na reprodução social. Magalhães (2013, p.48) evidencia o papel das classes dominantes na cidade de São Paulo nos anos de 1930 ao avalizar o que se entendia como assentamentos populares ilegais. No Rio de Janeiro, capital federal até a inauguração de Brasília em 1960, o Código de Obras de 1937 reconhece oficialmente a existência de favelas e classifica sua natureza como ilegal. Tal reconhecimento irá se materializar, por exemplo, nas primeiras contagens demográficas nestes territórios a partir da década de 1940.

É importante destacar que o reconhecimento das favelas não se configura necessariamente como uma regulação jurídica, muito menos como uma expressão oficial 
do urbano no país, isto é, como um reconhecimento de direito. A despeito da clássica representação de que as favelas surgiram à revelia do Estado, que seriam espaços anômicos, da ausência total de regras, a relação entre a formação destes territórios e a ação do poder público e do capital imobiliário de natureza especulativa é estreita. Nada trivial, então, que os discursos que se tornaram hegemônicos sobre tais espaços e seus moradores sejam crivados pelo paradigma da pobreza e da ausência, que as favelas sejam retratadas como problema urbano em diferentes abordagens das ciências humanas, que sejam pensadas como espaços da não cidade, da não urbanidade e, consequentemente, passíveis de intervenção.

Especificamente no atual momento, os grandes meios de comunicação têm noticiado a chegada da pandemia nas favelas e tem feito isso explicitando os riscos amplificados que pode proporcionar o desembarque da doença nas populosas periferias dos grandes centros urbanos do país.

Evidentemente que a gravidade das condições sociais e ambientais das cidades já é suficiente para que o noticiário se debruce sobre o contexto. Mas a aparente "novidade" noticiada não é, podemos assim dizer, algo novíssimo ou simplesmente conjuntural. As favelas já configuram as páginas jornalísticas como problema sanitário há mais tempo. A título de exemplo, basta observar o fragmento a seguir:

No entanto, apezar de possuir elementos honestos, a Favella é um antro de faccinoras e deve ser arrasado para decencia e hygiene da Capital Federal. (Reportagem da Revista Careta, de 04 de dezembro de 1909. Esta é a primeira vez que a o termo favela é utilizado na imprensa).

Lucien Parisse realça esta concepção e discurso de caráter higienista, que correlaciona as condições sociais marcadamente desiguais com uma questão de saúde mais ampla.

A Cidade olha a favela como uma realidade patológica, uma doença, uma praga, um quisto, uma calamidade pública. Estas expressões encontram-se em todos os jornais, sob a pena de jornalistas, professores, intelectuais, quer eles exprimam sua hostilidade à favela, ou declarem seus bons sentimentos, suas boas intenções.” (PARISSE, L. Favelas do Rio de Janeiro. Evolução-sentido. Cadernos do CENPHA, 5, 1969, p.36)

Se a realidade patológica do momento tem proporções mais globais, de outro modo o olhar sobre as periferias, nesse caso, sobre as favelas, isto é, esta construção simbólica do problema, permanece como uma representação social fortíssima, com incidência qualitativa sobre as políticas destinadas a tais territórios e populações. Nada trivial é falarmos de urbanizar as favelas, sanear as favelas, quando não se registra a opção redentora de sua erradicação em discursos de remoção, como estratégia para salvar as cidades desse mal. Por outro lado, ainda, as ações voltadas para as periferias no atual contexto de crise pandêmica tendem a enfatizar a precariedade, mas invisibilizar as bases desiguais que sustentam o urbanismo moderno.

Fica a dúvida se não carecemos de narrativas outras sobre as favelas, que, ao contrário do discurso higienista - como o que dominou o cenário carioca no início do século $\mathrm{XX}$, quando as elites dominantes e influentes daquele momento, conseguiram impingir aos estratos mais vulneráveis da população, especialmente os que residiam em favelas, uma condição subalternizada - nos permita repensar a vida urbana exatamente a partir dos mais simples que nela residem. 


\section{A periferia não cabe nos consensos urbanos}

Historicamente, periferias e favelas ganham destaque nos estudos das ciências humanas como produtos socioespaciais modernos relativos ao espaço produzido sob a égide do modo de produção do capital. Lefebvre (2001) apresenta a industrialização e a urbanização como processos correlatos, de modo a apontar que temos uma sociedade urbana a nossa volta em face aos efeitos destes dois grandes fenômenos.

De fato, a cidade é anterior ao processo de industrialização. Contudo, o processo de desenvolvimento do capitalismo se traduziu em uma formação social marcada pela centralização econômica de negócios e pela concentração geográfica dos fatores da produção e reprodução do capital (SEABRA, 2009) ${ }^{2}$. Com isso as estruturas mais antigas que mesclam diferentes usos e classes se alteram, são capturadas pela lógica da produção, circulação e consumo capitalista.

O espaço, como produto social, condicionado por tais referenciais, revela-se através da contradição valor de uso/valor de troca. O tecido urbano, tal como afirma Lefebvre (2001) se constitui como um suporte para um modo de vida marcado pelo que ele define como sociedade urbana. E na medida em que o espaço urbano vai se tornando cada vez mais objeto, mercadoria, esta base territorial se transforma rapidamente. $\mathrm{O}$ circuito de produção e consumo estabelecido como modelo de sociedade se estabelece no espaço urbano. Refém desta lógica, natureza vira recurso, solo urbano vira mercadoria, os sujeitos tornam-se engrenagens do processo produtivo e, consequentemente, a urbanização cede espaço para uma lógica funcional e se torna um fenômeno de classe (HARVEY, 2014)

Diante da centralidade da vida urbana sob esta ótica, escapam as frações espaciais e sociais que integram o urbano. As traduções mais recorrentes evidenciam bairros periféricos e favelas como excrescências. Embora compreendam seu lugar nas engrenagens produtivas, majoritariamente interpreta-os como espaços abaixo da normalidade, um desvio social e econômico.

Se adotamos como recurso teórico-metodológico para análise deste fenômeno a noção de produção e reprodução do espaço, tal como aponta Lefebvre, é pertinente considerar que no plano da produção capitalista podemos falar da materialidade, das formas como o capital transformou o espaço a fim de sua própria reprodução e, neste sentido, cabem os estudos sobre os fatores locacionais da produção, dos sistemas/circuitos produtivos, dos impactos relevantes disto na formação das grandes cidades, metrópoles, megacidades. Mas, por outro lado, é indispensável que se destaque também a produção das relações sociais e de como isso incide sobre a produção do espaço urbano.

De modo similar, em $O$ direito à cidade, Lefebvre revela como formas e funções urbanas vão se alterando e produzindo novas estruturas. Então os arranjos produtivos a serviço da acumulação de capital devem ser compreendidos não simplesmente em si, mas no contexto social em que são produzidos. Isto é, há uma produção social do espaço que se manifesta permanentemente na reprodução destas estruturas. Nenhuma materialidade se transforma sem que seja acompanhada por conversão das relações entre os sujeitos e destes com o espaço em que vivem. É preciso que haja um movimento no pensamento e na ação para que as estruturas se consolidem. Entretanto, este movimento não é linear ou mesmo coerente, mas acontece a partir das lutas de classe, das disputas ideológicas, das estratégias de reprodução social de cada grupo social em seus contextos de vida.

Neste sentido, considerando a finalidade deste trabalho, cidade e o urbano são atravessados por essas contradições. Se de alguma forma a cidade moderna emerge a partir de uma lógica objetiva, como apresenta Arantes (2017), em que os consensos sobre urbano implicam num pensamento único para entender, planejar, organizar e produzir as 
cidades num contexto de sociedade urbana, por outro lado, uma análise qualitativa da realidade nos permite enxergar a produção dos espaços em conflito, fazer um mergulho no cotidiano, ou como nos aponta Santos (1999), tomar o espaço banal como desafio da investigação dos geógrafos.

Retomando a ideia das excrescências, os discursos de pobreza, desordem, ilegalidade, patologia, que são tão aplicados em estudos quando se fala das favelas, se alimentam desta lógica dominante para pensar as cidades, em especial, as grandes cidades. São comuns as traduções de favelas que utilizam terminologias como espaços de exclusão, da segregação urbana, a não-cidade. Outros de caráter mais social que entendem os seus moradores como pobres, vítimas do sistema ou mesmo como à margem social.

Uma versão plenamente contemporânea disso se dá pela narrativa das grandes mídias quanto ao protocolo de isolamento social imposto como medida de combate à disseminação da infecção causada pelo novo coronavírus. Ao mencionarem as favelas e periferias dos grandes centros assinalam que estes moradores são os que menos cumprem as medidas de isolamento. Simultaneamente, ao noticiarem a reabertura dos shoppings centers, se contentam a dizer que são medidas de relaxamento do protocolo que podem colocar em risco a sociedade. Isto é, a primeira situação tem identificação e endereço, mas a segunda é totalmente genérica. O mínimo que se poderia esperar é ventilar as possibilidades que os moradores de periferia têm para cumprir os protocolos, quando não indagar cada um dos ouvintes sobre as condições de trabalho a que boa parcela desta população está submetida, ainda mais exposta e fragilizada no atual momento.

Mas retomando a questão urbana, ao considerar o rápido processo de urbanização brasileira, conforme mencionamos anteriormente, as políticas de habitação popular não acompanharam o ritmo de crescimento das cidades. Em especial no Rio de Janeiro e São Paulo, cidades que receberam grande fluxo populacional, o crescimento de periferias e favelas foi bastante expressivo.

Silva e Barbosa (2005) salientam que esta urbanização era veloz e discricionária, uma vez que os investimentos em políticas urbanas eram expressivamente desiguais, promovendo a concentração de recursos em determinados setores produtivos, localidades e classes sociais. Tais assimetrias nas condições de urbanidade são implacáveis sobre o acesso a direitos básicos, como também para a produção de representações estereotipadas sobre as favelas e seus moradores.

Se habitar é a forma mais imediata pela qual os indivíduos se apropriam do espaço (Volochko, 2015), a marca mais explícita das favelas é seu caráter auto-construtivo. Os moradores assumiram, com seus próprios recursos, a construção de suas moradas para manter seu direito de permanecer na cidade. Diante da insuficiência das políticas públicas do Estado Brasileiro para habitação popular e das condições sociais de boa parcela da população de baixa renda, a autoconstrução tornou-se uma estratégia para reprodução social dos mesmos.

Outros autores trouxeram contribuições muito valiosas para esta historiografia, de modo que queremos nos deter no processo de luta e permanência das favelas e seus moradores nas cidades brasileiras, em especial, nas grandes metrópoles do Sudeste.

Ao colocar em questão a concepção dominante de cidade, que parece ser visitada e reivindicada a cada momento de crise urbana, queremos dar ênfase ao direito à morada por parte das classes populares que residem em favelas, mas especialmente salientar que a luta pela permanência na cidade não se constitui exclusivamente como enfrentamento ao que estava posto.

Além disso, precisamos realçar a enorme capacidade de criar no seio da cidade, nas áreas que não foram inicialmente interessantes ao capital imobiliário especulativo, uma forma de habitação popular genuína, forjada a partir dos contextos concretos de vida 
de seus residentes. Seja em encostas, em áreas próximas a córregos e rios, em baixadas, cada pedaço de terra disponível que pudesse garantir abrigo e sobrevivência em contexto de déficit de investimentos públicos e privados, foi ocupado por cidadãos e cidadãs como estratégia para garantir sua própria dignidade.

Por vezes as interpelações advindas da ciência, da política e dos meios de comunicação trataram este processo a partir da concepção dominante de urbano. Com isso as narrativas tiveram, em sua maioria, caráter acusatório e condenatório sobre as estratégias e práticas sociais dos moradores destas periferias. Certamente tais narrativas tinham como substrato a visão elitista da cidade, marcadamente discricionária não apenas por uma questão econômica, mas também pela sua natureza racializada, isto é, por expressar a histórica posição de superioridade em termos econômicos, também simbolicamente, dos brancos sobre as populações negras que habitam as cidades.

A despeito dessas narrativas, tomadas aparentemente como corretas por parte do próprio poder público, os grupos populares tiveram sabedoria para burlar as normativas urbanísticas e consolidar usos e práticas concernentes a sua condição de vida. Por exemplo, a exiguidade do espaço construtivo foi compensada com o compartilhamento cotidiano dos espaços públicos. A quase ausência de espaços de lazer foi amenizada pela vida social permitida na laje de suas casas. A indiferença do poder público quanto à dotação de infraestrutura básica foi respondida com a luta e mobilização em associações de moradores combativas, que foram vitoriosas não somente no enfrentamento de vários episódios de remoção, como tiveram conquistas diversas para suas condições ambientais de habitabilidade.

Deste modo, é preciso reconhecer que estratégias adotadas por estes moradores obtiveram sucesso para seu exercício do direito à cidade, e os estudos direcionados a entendê-las precisam revisar determinadas categorias epistemológicas e instrumentos de interpretação da realidade, sob pena de obliterar um urbanismo subalterno, oriundo das periferias. Em outras palavras, as velhas definições de uma periferia gravitando em torno do centro ou de um subalterno caracterizado pela incapacidade de exercício da sua condição de sujeito precisam ser revisadas.

Roy (2017), na tentativa de suplantar as teorias urbanas mais convencionais, aciona o que ela define como um urbanismo subalterno. Apesar das tensões que isso implica, a autora insiste na crítica ao paradigma dominante de urbano que pode implicar na invisibilidade de práticas inventivas e, muito mais, num embotamento dos estudos sobre as cidades do Sul global. A pesquisadora americana destaca as formas próprias de ordenamento territorial das favelas, que as teorias urbanas podem não enxergar ou mesmo negligenciar. Tomando como exemplo diferentes estudos urbanos em favelas situadas em grandes cidades de países subdesenvolvidos e com base na teoria pós-colonial, a autora tenta construir um percurso para reconhecer elementos deste ordenamento, uma espécie de "agência popular", que a seu entendimento é um deslocamento do subalterno da condição da pobreza e da anomia, algo que já nos referimos anteriormente.

Embora circulem em torno da ideia do agenciamento, um conjunto muito variado de leituras e interpretações - desde as que acentuam o caráter econômico centrado no modelo da economia empreendedora das periferias àquelas que valorizam a condição política dos sujeitos que se assenhoram de suas vidas e territórios e constroem novas narrativas sobre estes- nos interessa pensar as periferias sob outro paradigma, principalmente neste momento em que a sociedade deve olhar para si, como se tivesse olhando no espelho, para reconhecer os traços de sua história registrados em sua imagem e retomar o significado da vida humana para todos. 


\section{Por fim, podemos repensar as cidades a partir da favela?}

Torna-se dramática a constatação de que a chegada da pandemia do novo coronavírus nas favelas e periferias poderá ter efeito devastador. Mesmo que façamos uma defesa intransigente da legitimidade destes territórios na cidade, reconhecemos que as condições de desigualdade vivida por boa parte de seus moradores trazem consequiências ameaçadoras a sua existência.

Um rápido levantamento das condições ambientais, dos padrões construtivos em favelas já demonstra a quantidade de residentes compartilhando os mesmos cômodos, as habitações com restrições quanto à iluminação e ventilação, o acesso parcial à água potável, entre outros. Outro componente estruturante é a presença majoritária de trabalhadores e trabalhadoras em funções profissionais subalternizadas no mercado, além do elevado número destes em condições de desemprego, subemprego e informalidade. São estes mesmos trabalhadores que não estão tendo opção de permanecer isolados, sob pena de interrupção, talvez, da única fonte de renda.

Cabe destacar ainda que o caráter de controle e coerção social, historicamente praticado pelo Estado, mas que nas favelas se reveste, sobretudo, por estratégia militarizada, somado aos constrangimentos vividos pelos moradores de periferias nas mais diversas instituições públicas onde buscam algum atendimento, proporciona uma baixíssima expectativa sobre o exercício do direito, o que tende a afastar muitos destes da busca de informação e acesso a serviços essenciais.

Ainda que este cenário seja relevante e indispensável para que qualquer política pública ou programa emergencial seja disparado, como podemos atuar sobre as catástrofes que se abatem sobre nós e ao mesmo tempo avançar nas mudanças estruturais que precisamos fazer? Após a pandemia, retomar as mesmas concepções de um urbanismo consorciado aos grandes interesses econômicos é manter os padrões que nos levaram às atuais condições.

Se não, vejamos que as periferias e favelas têm sido bastante efetivas em indicar alguns caminhos. Queremos, então, apresentar algumas observações e indagações com base nestas respostas produzidas a contrapelo das representações dominantes sobre estes territórios.

O primeiro elemento é relativo à paisagem da favela. Não é trivial que o noticiário apresente os riscos iminentes asseverando as condições de habitação destes territórios.

Em geral essas representações subtraem um elemento característico das favelas, ou seja, sua pluralidade. É comum que todas as favelas sejam vistas como iguais, inclusive para fins de propostas urbanísticas. A relação que se estabelece, então, é de subordinação. No exercício do poder, o Estado tem a prerrogativa para agir com base em suas próprias conveniências. É comum que os padrões de intervenção não sejam os mesmos que os praticados em outras partes da cidade. A experiência do Programa Favela-bairro, na cidade do Rio de Janeiro constitui um exemplo do que estamos falando. Praticamente não houve debate na sociedade sobre seu desenho, “(...) o programa saiu quase que em linha reta das pranchetas dos técnicos da prefeitura e dos escritórios de arquitetura para as favelas..." (BURGOS, 2006, p. 51)

A paisagem das favelas é expressão da dinâmica urbana brasileira. A incompletude das políticas e ações do Estado é proporcional ao movimento das classes populares em inventar um espaço o mais acolhedor e qualificado possível. Consequentemente o urbano produzido não atende a requisitos considerados mínimos do ponto de vista técnico, jurídico e político, mas conferem a seus idealizadores abrigo, identidade e convivência. É imprescindível que nos voltemos para isso suplantando um urbanismo que atende às expectativas de reprodução do capital especulativo nas cidades, 
porém esvazia cada um de nós da condição de co-responsáveis pela obra urbana. Tal como aponta Harvey, em nossa capacidade de transformá-la naquilo que nos atende em nossos mais profundos desejos (HARVEY, 2014, p.28).

Convém, portanto, nos indagar sobre a diversidade de sítios urbanos. Em que medida nossas leituras e proposições sobre a cidade e o urbano têm incorporado os arranjos e práticas da periferia? Porque estas práticas estão grafadas nas ruas, becos, nos espaços compartilhados de modo insistente e desobediente. São elementos da paisagem cotidiana que estão incorporados aos hábitos dos moradores. A isso Roy (2017) recupera a proposição de Asef Bayat, professor de origem iraniana-americana que descreve as favelas como espaços marcados por aquilo que ele define como vida informal, caracterizado por um jogo de negociações frente à luta pela sobrevivência. Para o estudioso seria o habitus dos despossuídos, numa referência ao conceito desenvolvido pelo sociólogo francês Pierre Bourdieu. Assim, em que medida essa trama urbana grafada na paisagem da favela pode ser incorporada como parte indissociável do nosso fazer político e nas políticas públicas efetivas de transformação urbana nas favelas?

Desdobra-se disso o debate sobre o urbano no seu conjunto. Esta produção, ainda que realizada em meio às relações sociais, pode ser apropriada privativamente. Usos e acessos ao espaço convertem-se em projeto do mercado, dos interesses financeiros. Com isso a cidade torna-se refratária aos sujeitos concretos, territorialmente referenciados. Carlos assinala este processo em que a "obra humana se opõe ao humano" (CARLOS, 2015. p.13).

As cidades devem ser pensadas e redesenhadas a partir de todos os seus territórios. As políticas urbanas não podem ser limitadas ao agenciamento de negócios, tendo a cidade como um ativo próspero num mercado competitivo, sob o risco de produzirmos ainda mais estratificação. A respeito disso, os moradores de favelas, a despeito da insuficiente ação do poder público em oferecer habitação popular através de políticas públicas eficazes, desenvolveram suas estratégias de moradia. Autoconstrução, aluguel de casas, ocupação de galpões abandonados, a verticalização das casas ou as ampliações em conjuntos habitacionais, os famosos "puxadinhos", se tornaram soluções próprias ao déficit habitacional do país.

O caráter mais espontâneo das construções nas favelas é descrito nos padrões urbanos oficiais como irregularidade e é tomado como referência para justificar, por exemplo, os limites para que conjunto de direitos ordinários alcance o morador. A água não chega porque não há rede oficial. Os correios não chegam, porque não há sistema de endereçamento reconhecível. A eletrificação é oscilante, porque a rede é caótica e assim por diante. Em outras palavras, o direito fica capturado por uma concepção limitada de cidadão. Barbosa (2016) assinala a experiência urbana marcada pela distinção territorial de direitos, de modo que morar nas distantes periferias ou favelas dos grandes centros urbanos afeta sobremaneira as condições para o sujeito exercer seus direitos.

Outro elemento que parece estruturar o noticiário da pandemia nas favelas tem seu viés humanitário. Sobre isso queremos explicitar nosso posicionamento a favor das ações assistenciais que estão em curso, principalmente porque essas são necessárias e nos colocam frente a uma dimensão humana mais geral, de co-responsabilidade que todos temos com a sociedade, independente das condições sociais, da origem etc.

Contudo, é indispensável que o clamor pela solidariedade não embote nossa capacidade de criticar algo que é tão recorrente em relação às favelas, ou seja, o discurso da incivilidade, da ausência. A concepção de que as pessoas seriam incapazes de alterar sua condição de existência é visitada regularmente a cada grande catástrofe social na cidade e agora não é diferente. A subalternidade capturada por esta ótica é completamente 
alheia às histórias de luta contra o assujeitamento que estão presentes neste urbanismo subalterno que nos referimos anteriormente.

As favelas são conhecidas por seu alto grau de sociabilidade entre moradores, em parte proporcionado pelas relações de parentesco e de vizinhança onde a amizade tende a se manifestar mais claramente e as relações de solidariedade são fundamentais para sobreviver diante das condições de desigualdade que enfrentam. É fato que este tipo de sociabilidade também pode ser capturado por grupos distintos, inclusive grupos civis e paramilitares armados, que exploram o território como estratégia de reprodução dos negócios. Mas, independente disso, o convívio, mesmo que não desprovido de conflitos, é um traço distintivo das periferias e favelas que colocam em questão esta percepção de sua incivilidade.

Mas, os obstáculos impostos a estas pessoas foram progressivamente sendo ultrapassados. O movimento associativo protagonizou muitas lutas, que hoje estão no escopo de atuação de organizações da sociedade civil e coletivos originários nas próprias periferias. E aqui reside, para nós, outro elemento altamente potente e ser destacado. Nas favelas temos um sujeito coletivo que, gradualmente, foi se tornando fundamental para travar novos horizontes para estes territórios. Existe um urbanismo militante em coletivos culturais, ONGs, movimentos de mulheres, de jovens, de lideranças comunitárias que se tornaram importantes interlocutores para qualquer ação positiva em seus territórios.

Atualmente estamos vendo isso com esta crise provocada pela pandemia. A atuação de organizações da sociedade civil, dos coletivos e movimentos sociais locais mostra-se cada vez mais imprescindível na difusão de informações, no combate à disseminação do vírus e no apoio às famílias mais vulneráveis que residem nos territórios.

Entendemos que este seja um legado importante que estas formas de mobilização deixam. Há uma arena política de inventividade, de participação e de incidência que pode iluminar nossos caminhos em torno de um projeto de cidade mais integrado e com plena participação da sociedade civil.

Ainda no esteio desse urbanismo potente das periferias é oportuno salientar algumas das centralidades que as ressignificam. Se teoricamente as favelas são interpretadas como espaços pouco atrativos, aglomerados de casas e pessoas, ambientes de pouca ou nenhuma cultura, o mosaico de sujeitos, histórias, práticas e arranjos sociais produzidos nestes espaços supera, em muito, o que se escreve e fala deles.

A noção de aglomerado pode estar assentada na concepção da irregularidade e no clássico paradigma do que seja a habitação. Habitar na favela não se restringe ao uso residencial. Aliás, o espaço público é a extensão das casas e qualifica bastante a vida dos moradores. Contudo, as residências têm múltiplos usos na favela. Elas se ampliam verticalmente e no primeiro andar viram pequenos negócios, estratégicos para a reprodução da vida das famílias.

Mais uma vez neste momento em que uma parcela destas famílias necessita de auxílio para enfrentar a pandemia, é este comércio local, próximo, conhecido que tem dado suporte material a determinadas demandas dos moradores.

As mesmas organizações e coletivos, que já foram mencionadas anteriormente, protagonizam momentos de lazer, cultura, impactando sensivelmente o tal simbólico de território sem arte e cultura. Poderíamos elencar aqui uma lista de grupos e organizações que atualmente cumprem um papel político fundamental nestes territórios, ampliando tempo e espaço de moradores e sinalizando para que estes se sintam mais parte da cidade, contrapondo-se aos ultrapassados discursos da cidade informal.

Por fim, definitivamente não temos condições de esgotar este debate. Muitas análises podem ser construídas neste momento a respeito do futuro das cidades num contexto de enfrentamento de crises, como a atual pandemia. Todavia, nenhum caminho 
que possamos trilhar no sentido de pensar as cidades e nossos processos urbanos pode ser feito sem agregar todos os territórios, sem reconhecer nas diferenças entre estes uma oportunidade para fortalecer os laços de convivência e promover justiça em suas mais diferentes dimensões. As oportunidades podem facilmente escapar de nossas mãos. Que saibamos aproveitá-la com sabedoria!!

\section{Notas}

1 - Para fins de compreensão, aglomerado subnormal é uma classificação adotada pelo IBGE para caracterizar áreas como favelas, vilas, mocambos, invasões, comunidades, grotões, em geral, espaços populares. Para maior detalhamento da definição ver https://www.ibge.gov.br/geociencias/organizacao-do-territorio/tipologias-doterritorio/15788-aglomerados-subnormais.html?=\&t=0-que-e.

2 - In CIDADES: Revista Científica / Grupo de Estudos Urbanos - Vol , n. 10, 2009

3 - In ZALUAR, A., ALVITO, M. (orgs.). Um século de favela. 5 ed. Rio de Janeiro: Editora FGV, 2006.

\section{Referências Bibliográficas}

ABREU, M.de A. A evolução urbana do Rio de Janeiro. Rio de Janeiro: IPLANRIO, 1997.

ARANTES, Otília Beatriz Fiori. Urbanismo e fim de linha e outros estudos sobre o colapso da modernização arquitetônica. São Paulo: Editora da USP, 1998.

ARANTES, O.,VAINER, C., MARICATO, E. A cidade do pensamento único: demanchando consensos. 8 ed. Petrópolis, RJ:Vozes, 2013

BARBOSA, J. L. O significado da mobilidade na construção democrática da cidade. In: BALBIM, R; KRAUSE, C; LINK, C.C. (orgs.) Cidade e Movimento: mobilidades e interações no desenvolvimento urbano. Brasília: IPEA:ITDP, 2016.

CAMPOS, A. Do quilombo à favela: a produção do "espaço criminalizado" no Rio de Janeiro. Rio de Janeiro: Bertrand Brasil, 2005

CARLOS, A.F.A. A (Re)Produção do Espaço Urbano. São Paulo: Editora da Universidade de São Paulo, 1994.

DAVIS, M. Planeta Favela. Tradução: de Beatriz Medina. São Paulo: Boitempo, 2006.

GONÇALVES, R. S. Favelas do Rio de Janeiro: história e direito. Rio de Janeiro: Pallas: Editora PUC-Rio, 2013

HARVEY, D. Cidades Rebeldes: do direito à cidade à renovação urbana. São Paulo: Martins Fontes - selo Martins, 2014.

LEEDS, A.; LEEDS, E. A sociologia do Brasil urbano. 2 ed.,ver - Rio de Janeiro: Editora Fiocruz, 2015

LEFEBVRE, Henri. A cidade do capital. Tradução de Maria Helena Rauta Ramos e Marilena Jamur. Rio de Janeiro: DP\&A Editora, 1999.

A revolução urbana. Tradução de Sérgio Martins. Belo Horizonte:

Editora UFMG, 1999

La production de l'espace. 4e éd. Paris: Éditions Anthropos, 2000.

. O direito à cidade. Tradução de Rubens Eduardo Frias. São Paulo:

Editora Centauro, 2001.

MAGALHÃES, A. F. O direito das favelas. Rio de Janeiro: Letra Capital, 2015.

PARISSE, L. Favelas do Rio de Janeiro: evolução-sentido. Rio de Janeiro: Caderno do CENPHA, n.5, 1969. 
ROY, A. Cidades faveladas: repensando o urbanismo subalterno. Revista Eletrônica Emetropolis. N. 31. Ano 8. Rio de Janeiro. Dezembro de 2017

SANTOS, M. A natureza do espaço: espaço e tempo: razão e emoção. $3^{a}$ Ed. São Paulo: Editora Hucitec, 1999.

SANTOS, M. A urbanização desigual: a especificidade do fenômeno urbano em países subdesenvolvidos. 3 ed. 1. Reimp. - São Paulo: Editora da Universidade de São Paulo, 2012.

SEABRA, O. C. de L. Metropolização: a reprodução do urbano na crise da sociedade do trabalho. In: REVISTA CIDADES. Vol 6. N. 10. Presidente Prudente: Grupo de Estudos Urbanos, 2009.

SILVA, Jailson Souza \& BARBOSA, Jorge Luiz. Favela: Alegria e Dor na Cidade. Rio de Janeiro: Editora SENAC Rio; [X] Brasil, 2005

VALLADARES, L.do P. A invenção da favela: do mito de origem a favela.com. Rio de Janeiro: Editora FGV, 2005.

VOLOCHKO, D. Nova produção das periferias urbanas e reprodução do cotidiano. In: CARLOS, A.F.A (org). A. Crise Urbana. São Paulo: Contexto, 2015

ZALUAR, A., ALVITO, M. (orgs.). Um século de favela. 5 ed. Rio de Janeiro: Editora FGV, 2006. 